\title{
Performance of Generalist and Specialist Herbivores and their Endoparasitoids Differs on Cultivated and Wild Brassica Populations
}

\author{
Rieta Gols • Tibor Bukovinszky • Nicole M. van Dam • \\ Marcel Dicke • James M. Bullock • Jeffrey A. Harvey
}

Received: 6 March 2007 /Revised: 26 December 2007 / Accepted: 7 January 2008 / Published online: 30 January 2008

(C) The Author(s) 2008

\begin{abstract}
Through artificial selection, domesticated plants often contain modified levels of primary and secondary metabolites compared to their wild progenitors. It is hypothesized that the changed chemistry of cultivated plants will affect the performance of insects associated with these plants. In this paper, the development of several specialist and generalist herbivores and their endoparasitoids were compared when reared on a wild and cultivated population of cabbage, Brassica oleracea, and a recently established feral Brassica species. Irrespective of insect species or the degree of dietary specialization, herbivores and parasitoids developed most poorly on the wild population. For the specialists, plant population influenced only development time and adult body mass, whereas for the generalists, plant populations also affected egg-to-adult survival. Two parasitoid species, a generalist (Diadegma fenestrale) and a specialist (D. semiclausum), were reared from the same host (Plutella xylostella). Performance of $D$. semiclausum was closely linked to that of its host, whereas the correlation between survival of $D$. fenestrale and host performance was less clear. Plants in the Brassicaceae characteristically produce defense-related
\end{abstract}

R. Gols $(\bowtie) \cdot$ T. Bukovinszky $\cdot$ M. Dicke

Laboratory of Entomology, Plant Science Group,

Wageningen University,

Wageningen, The Netherlands

e-mail: rieta.gols@wur.nl

N. M. van Dam · J. A. Harvey

Department of Multitrophic Interactions,

Centre for Terrestrial Ecology, Netherlands Institute of Ecology,

Heteren, The Netherlands

J. M. Bullock

Centre for Ecology and Hydrology,

Wallingford, Oxfordshire, UK glucosinolates (GS). Levels of GS in leaves of undamaged plants were significantly higher in plants from the wild population than from the domesticated populations. Moreover, total GS concentrations increased significantly in wild plants after herbivory, but not in domesticated or feral plants. The results of this study reveal that a cabbage cultivar and plants from a wild cabbage population exhibit significant differences in quality in terms of their effects on the growth and development of insect herbivores and their natural enemies. Although cultivated plants have proved to be model systems in agroecology, we argue that some caution should be applied to evolutionary explanations derived from studies on domesticated plants, unless some knowledge exists on the history of the system under investigation.

Keywords Crucifer Diadegma fenestrale - Diadegma semiclausum - Direct defense · Glucosinolates · Induction . Mamestra brassicae $\cdot$ Pieris rapae $\cdot$ Plutella xylostella

\section{Introduction}

The occurrence of pests in agroecosystems has long promoted the study of insect-plant interactions in crop plants, such as cabbage, lima bean, maize, cotton, and tomato (Takabayashi et al. 1994; Turlings et al. 1995; De Moraes et al. 1998; Geervliet et al. 2000; Thaler et al. 2001). Studies with crop plants have generated a wealth of data, highlighting a number of important mechanisms that influence the structure and function of multitrophic interactions and communities (Root 1973; Sheehan 1986; Khan et al. 1997; Gols et al. 2005). However, critics have argued that the biology and ecology of crop plants is often dramatically different from wild populations, thus bringing 
into some question the evolutionary relevance of the conclusions generated from data that rely on crop plants (Benrey et al. 1998; van der Meijden and Klinkhamer 2000). For instance, plant breeding programs have been reported to disrupt the original plant defense strategies that were present in the wild progenitors of cultivated species (Evans 1993). Artificial selection of some crop plants, aimed at accentuating a specific plant trait or group of traits (e.g., the production of edible structures), has been shown to reduce the level of undesired constituents, such as defense compounds, while enhancing others (such as primary metabolites including proteins and sugars). Many of the undesired secondary plant compounds (SPC) are known to have evolved and function as putative defenses against herbivores, whereas the desired primary plant compounds act as nutrients and thus may actually enhance the performance of herbivores (Schoonhoven et al. 2005).

Levels of SPC are dynamic and vary with such factors as season, soil conditions, and leaf age (reviewed by Schoonhoven et al. 2005). Moreover, plants may increase their levels of defenses in response to feeding damage (Karban and Baldwin 1997; Agrawal 1999a), which may reduce the costs of defenses by avoiding the allocation of resources to defense when the attacker is absent. Secondary plant compounds have also been shown to affect negatively the development of higher trophic levels that attack these herbivores, such as predators, parasitoids, and even hyperparasitoids (Barbosa et al. 1986, 1991; Francis et al. 2001; Harvey et al. 2003, 2005, 2007; Ode et al. 2004). Consequently, changes in plant chemistry, mediated by artificial selection, may influence the behavior and development of consumers over several trophic levels, and this may ultimately lead to broader effects on the communities associated with these plants (Harvey et al. 2003; Ode 2006). Most importantly, in wild plants, defense mechanisms have not been constrained by the "directional selection" that characterizes many crop plants. Therefore, to understand the evolution of plant defenses against insect herbivores, multitrophic interactions should also be studied in wild conspecifics of the cultivated plant species where plant defenses are the likely result of a range of biotic and abiotic selection pressures.

One appropriate plant family for studying the effects of artificial versus natural selection on multitrophic interactions is the Brassicaceae, which contains such important crops as cabbages and various types of mustard (GómezCampo and Prakash 1999). Of all plants that have been domesticated, few have been manipulated to produce so many different cultivars as Brassica oleracea L. (e.g., cabbage, broccoli, cauliflower, and Brussels sprout; Gómez-Campo and Prakash 1999). Wild types of $B$. oleracea grow naturally along rocky coastlines of Britain and France (Mitchell and Richards 1979). It has been speculated that the wild populations in the UK are derived from plants that were cultivated by the Greeks and Romans in the Mediterranean region between 1,000 and 2,000 BC (Mitchell 1976). These early cultivated forms were introduced to Britain, but have been naturalized for centuries (Mitchell 1976). However, more recent evidence points also at an Atlantic origin of domestication (Song et al. 1990).

Plants in the Brassicaceae characteristically produce secondary metabolites called glucosinolates (hereafter GS) (Fahey et al. 2002). After tissue damage, myrosinases catalyze the hydrolysis of GS into (iso)thiocyanates and nitriles (Mithen 2001; Fahey et al. 2002), which play a role in defense against insect herbivores (Rask et al. 2000). Generalist herbivores produce enzymes that can detoxify a wide range of substrates (Krieger et al. 1971), whereas specialists have evolved enzyme systems that can detoxify specific plant compounds that are associated with herbivore diet (e.g., Johnson 1999; Ratzka et al. 2002). Thus, generalist herbivores are usually more sensitive to high levels of specific allelochemicals compared to specialists. (see e.g., Blau et al. 1978; Giamoustaris and Mithen 1995).

Specialist feeding on brassicaceous plants are adapted to plants containing GS, and they detoxify, excrete, or even sequester these harmful metabolites (Müller et al. 2001; Ratzka et al. 2002; Wittstock et al. 2004). Moreover, some insects use these compounds as indicators of food plant suitability (Nayar and Thorsteinson 1963; Renwick and Lopez 1999). Not all GS are equally effective as stimulants, and high levels of GS can reduce the performance of herbivores that are specialized on brassicaceous species (Stowe 1998; Li et al. 2000; Traw and Dawson 2002; Agrawal and Kurashige 2003). In addition, GS concentrations can increase in response to herbivore feeding damage (Bodnaryk 1992; Agrawal 1999b) and negatively affect subsequent herbivory by both generalists and specialists (Agrawal 1999b; Bartlet et al. 1999; Traw and Dawson 2002).

This study compares the development of several species of herbivores and endoparasitoids when reared on three Brassica populations that differ in their degree of domestication. Insects were reared on a cultivated and a wild population of B. oleracea, and a recently escaped (feral) Brassica species. Levels of GS were measured as indicators of direct plant defense. Initially, the development of two specialists on Brassicaceae, Plutella xylostella L. (Lepidoptera: Plutellidae) and Pieris rapae L. (Lepidoptera: Pieridae), and a generalist herbivore, Mamestra brassicae L. (Lepidoptera: Noctuidae), were examined when reared on the three populations. Finally, the development of a specialist and generalist parasitoid reared on the same host, P. xylostella, were compared. Separate cohorts of $P$. xylostella were parasitized by two species of endoparasitoids, Diadegma semiclausum Hellén (Hymenoptera: Ich- 
neumonidae) and a related species, D. fenestrale Holmgren (Hymenoptera: Ichneumonidae). These two parasitoids differ in host specialization, with D. semiclausum restricted to P. xylostella and D. fenestrale attacking several other hosts that feed on non-brassicaceous species (Legaspi 1986; Azidah et al. 2000).

The following hypothesis was tested: specialist herbivores and parasitoids are less affected than generalists by differences in host plant chemistry between various Brassica populations that differ in their degree of domestication. It is proposed that changes in plant biology via domestication have significant effects on community level interactions and processes.

\section{Methods and Materials}

Plants The B. oleracea variety gemmifera (Brussels sprout) cv. Cyrus was used. Compared to other vegetable crops of $B$. oleracea, Brussels sprout cultivars contain relatively high levels of GS (Kushad et al. 1999; Rosa 1999), but considerably lower levels than the wild $B$. oleracea populations in Dorset, Great Britain (Moyes et al. 2000; Gols et al. 2008). Seeds from several plants $(>10)$ were collected from a wild population of $B$. oleracea growing on chalk cliffs along the south coast of Great Britain, near Swanage, Dorset (“Old Harry," $50^{\circ} 38^{\prime} \mathrm{N}, 1^{\circ} 55^{\prime} \mathrm{E}$ ). This population contains intermediate levels of GS compared to other Dorset wild populations (Moyes et al. 2000). A feral Brassica population, which was found in a roadside hollow about $15 \mathrm{~km}$ east of Wageningen $\left(51^{\circ} 95^{\prime} \mathrm{N}, 5^{\circ} 78^{\prime} \mathrm{E}\right.$, The Netherlands), was also included.

In addition to comparing the development of different herbivores, we also compared the development of a specialist and generalist parasitoid reared on the same host (see section on Plutella xylostella and Diadegma species). To discriminate between food-plant quality mediated through the host and host quality itself, a second closely related wild brassicaceous plant species, black mustard, Brassica nigra L., was included in one of the experiments. Seeds of $B$. nigra were collected from a natural population growing in a small patch along the River Rhine, near Wageningen, The Netherlands $\left(51^{\circ} 94^{\prime} \mathrm{N}, 5^{\circ} 62^{\prime} \mathrm{E}\right)$.

Seeds from the different populations were germinated in the first week of March 2005. Seedlings were transferred to 1.11 pots filled with potting soil ("Lentse potgrond" no. 4, Lent, The Netherlands). Plants were grown in a greenhouse at $20-30^{\circ} \mathrm{C}, 40-80 \%$ r.h, with a photoperiod of at least $16 \mathrm{hr}$. If the light dropped below $500 \mu \mathrm{mol}$ photons $/ \mathrm{m}^{2} / \mathrm{sec}$ during the 16-hr photoperiod, supplementary illumination was supplied by high-pressure mercury lamps. Plants were watered daily. After the plants were 4 wk old, they were fertilized once a week with Kristalon Blauw (N-P-K) 19 6-20-3 micro $(2.5 \mathrm{mg} / \mathrm{l})$, which was applied to the soil. $B$. oleracea plants were $7 \mathrm{wk}$ old when they were used in experiments and attained similar amounts of biomass (25$30 \mathrm{~g}$ per plant). Plants from all three populations were in the vegetative state and developed new leaves during the experiments. Fertilization and watering continued during the experiments. Brassica nigra plants were $5 \mathrm{wk}$ old and were not fertilized because the soil still contained enough nutrients for optimal growth. B. nigra matures much faster than B. oleracea.

Insects All insects used originated from cabbage fields in the vicinity of Wageningen. Cultures of all the herbivores have been maintained in the laboratory on Brussels sprouts cv. Cyrus for many years in climate rooms at $22 \pm 2^{\circ} \mathrm{C}, 40$ $80 \%$ r.h, with a light regime of $16: 8 \mathrm{~L} / \mathrm{D}$. The two parasitoid species were collected in the summer of 2004 and were thereafter reared on plants heavily infested with $P$. xylostella larvae for several generations. After pupation on the walls of the rearing cage, parasitoid cocoons were carefully removed and transferred to a clean cage. Emerged adult wasps were provided with water and honey $a d$ libitum. For parasitism, we used females that were 5 to $10 \mathrm{~d}$ old after adult emergence.

Glucosinolate Analyses As an indicator of direct defense, GS concentrations in leaf tissues of $B$. oleracea were measured. Leaf samples were taken during the performance experiments (see below) from three treatment groups: plants that were undamaged, plants damaged by unparasitized P. xylostella, and plants damaged by larvae that had been parasitized by $D$. semiclausum. When leaf samples were taken, the damaged plant groups had been exposed to herbivore feeding for $7 \mathrm{~d}$. Undamaged control plants were maintained in the same greenhouse, but were physically separated from the plants with caterpillars. Larvae, feces, and pupae were removed from leaves. All fully developed leaves were harvested with the exception of the oldest leaves, which had turned yellow and did not contain feeding damage. Leaves were removed with a razor blade, pooled per plant, and stored at $-80^{\circ} \mathrm{C}$. Samples were later freeze-dried and pulverized with a mortar and pestle. Fifty milligram aliquots of freeze-dried material were weighed in 2-ml centrifuge tubes. GS were extracted and purified as described in van Dam et al. (2004) and were separated on a reverse phase C-18 column (Alltima C-18, $3 \mu \mathrm{m}, 150 \times$ $4.6 \mathrm{~mm}$, Alltech, Deerfield, IL, USA) on HPLC (Dionex, Sunnyvale, CA, USA) with an acetonitrile water gradient. Detection was performed with a DIONEX PDA-100 Photodiode array detector set to scan from 200 to $350 \mathrm{~nm}$. For quantification, sinigrin (Sigma, St. Louis, MO, USA) was used as an external standard. Peaks were integrated at 
$229 \mathrm{~nm}$, for which standard response factors have been defined (EC 1990). The different GS were identified based on their retention times, and UV spectra were compared to those of pure compounds (sinigrin, Sigma, St. Louis, MO, USA; glucotropaeolin and glucobrassicin were kindly provided by M. Reichelt, Max Planck Institute for Chemical Ecology, Jena, Germany), or compared to a certified oil seed reference (EC Community Bureau of Reference BCR-367R, Fluka, Buchs, Switzerland).

Insect Performance To investigate the effect of domestication on plant direct defenses, the different herbivores and parasitoids (see below) were reared on the three plant populations. For all insects, egg-to-adult development time, adult dry mass, and survival (to adult) were determined when reared on the different populations. Adult dry mass was obtained by weighing adults on a Cahn C-33 microbalance (Cahn Instruments, Cerritos, CA, USA) that had been dried to constant weight at $80^{\circ} \mathrm{C}(3 \mathrm{~d})$. Plants with insects were maintained in a greenhouse under the same conditions as described in the Plant section. Plants of the same population that received the same insect treatment were placed together, and caterpillars were allowed to develop and move around freely on plants until they reached the final instar. Different herbivore treatments were randomly positioned in a greenhouse, but were all placed in a similar position relative to the light sources to minimize microclimatic differences among plant populations and treatments.

Plutella xylostella and Diadegma Species To obtain eggs of P. xylostella, more than 150 adult moths were released with a $50: 50$ sex ratio in a plastic cage $(37 \times 40 \times 30 \mathrm{~cm})$. Folded strips of Parafilm served as substrate for females to lay eggs on. Females were allowed to oviposit on the Parafilm overnight. Subsequently, the strips with eggs were incubated for $4 \mathrm{~d}$ at $22^{\circ} \mathrm{C}$ until the eggs hatched. Pieces of Parafilm with neonate larvae were placed on top of individual plants of each of the three plant populations. Larvae were allowed to feed on these plants until they reached the third instar (L3).

For each plant population, one cohort of 60 larvae was transferred to new plants and served as an unparasitized control. A second cohort of 130 larvae was parasitized by D. semiclausum, and a third cohort of 180 larvae was parasitized by $D$. fenestrale. For parasitism, individual female wasps of both species were presented with a L3 $P$. xylostella host. A host was considered as parasitized when the female wasp was observed to insert into and remove her ovipositor from the larva. Individual female wasps were allowed to oviposit in up to 10 separate hosts. After this, they were removed. Parasitized larvae were transferred to new plants of the same population on which the larvae had fed previously. Five plants were used for the unparasitized controls and nine for each of the parasitoid treatments. The number of plants provided ample food for all larvae to complete their development.

When caterpillars molted into L4, strips of corrugated cardboard were placed on top of the plants, as P. xylostella prefers to pupate in secluded areas. After pupation, cocoons were collected and stored in labeled vials until adult emergence. When the moths or wasps emerged, the time of eclosion and sex were recorded. Individuals were killed by freezing at $-20^{\circ} \mathrm{C}$ and stored for dry mass determination. Vials with cocoons ready to emerge were checked every $2 \mathrm{hr}$. Development time for $P$. xylostella was measured in full days, as the exact time of oviposition had not been recorded. In the case of the two Diadegma species, the median time point of the period needed to parasitize the hosts (3-4 hr) was used as the time of oviposition.

To further investigate whether food plant quality or host quality was a more important factor in the development of D. fenestrale, the experiments described above with $P$. xylostella were repeated on a second (and closely related) wild brassicaceous species, B. nigra. A separate study (Gols et al. unpublished) has shown that $B$. nigra is a qualitatively superior plant for the development of $P$. xylostella, compared with B. oleracea. We reared 33 unparasitized larvae on three B. nigra plants, and 180 larvae parasitized by $D$. fenestrale on 10 plants. We recorded egg-to-adult development time, adult biomass, and survival as before. The plants provided ample food for all the larvae to complete their development.

Pieris rapae Neonate larvae were obtained from the general culture and transferred to seven plants of each population with a distribution of six larvae per plant. When larvae had developed into L5, they were transferred to plastic containers that contained some leaf material from the plants they had fed on previously. After pupation, pupae were collected and placed in new plastic containers lined with filter paper. At adult emergence, the time of eclosion and sex were recorded, and the individuals were killed by freezing, followed by dry mass determination (as above). Containers with pupae ready to emerge were checked every $2 \mathrm{hr}$. Development time was measured in full days, as the exact time of oviposition had not been recorded.

Mamestra brassicae Like P. xylostella, adult M. brassicae are primarily nocturnal. Females do not need plants as an oviposition substrate and readily lay batches of eggs onto the surface of paper. From the general culture, we obtained paper sheets with $M$. brassicae eggs that were laid the previous night. These sheets were incubated at $22 \pm 2^{\circ} \mathrm{C}$ (5 d) until the eggs hatched. Neonate larvae were transferred to 10 plants of each population, with a density 
of five larvae per plant. Once they had reached late L5, $M$. brassicae larvae were collected from the three populations, counted, and transferred to plastic containers $(15 \times 12 \times$ $6 \mathrm{~cm}$ ) that contained $2 \mathrm{~cm}$ of potting soil mixed with vermiculite $(1: 1)$ and some leaf material from the plant on which they had been feeding previously. After the larvae had pupated, they were collected and placed in new plastic containers filled with a layer of vermiculite. At moth emergence, the date of eclosion was recorded, and the individuals were killed by freezing, followed by dry mass determination. Containers with pupae ready to emerge were checked every $2 \mathrm{~h}$. Development was measured in full days as the exact time of oviposition had not been recorded.

Statistical Analysis Data on adult dry mass and development time were analyzed by using ANOVA with plant population and sex and their interaction as factors. All larvae within one plant population were considered as independent samples. The Tukey-Kramer method was used for multiple comparisons of the means. For each insect species, a $G$ test for heterogeneity was performed on survival rates of the three plant populations with $\mathrm{H}_{0}$ : survival on each of the three plant populations is equal.

Concentrations of individual GS compounds were log $(x+1)$ transformed to meet assumptions of normality. To examine differences in GS content, a Mixed Model was used with plant population and plant treatment (intact, damaged by unparasitized Plutella, damaged by parasitized Plutella) as the fixed factors in the model. There was no random factor in the analysis, and the estimation of effects in the model was based on restricted likelihood maximization. When the main factors or their interactions were significant, specific linear contrasts were applied to separate further factor levels. When necessary, correction for unbalanced sample sizes was carried out by using the Satterthwaite correction. Analysis was carried out with SAS 8.02 (1999-2001 CSAS Institute, Inc).

\section{Results}

Glucosinolate Analyses GS analyses of leaf tissues revealed considerable quantitative and some qualitative variation among the different Brassica populations (Fig. 1). Three pentyl-derived (C5) GS, glucoalyssin, gluconapoleiferin, and glucobrassicanapin were only detected in the feral population, whereas the other 10 compounds were present in all three populations (Fig. 1). Total GS concentrations in undamaged plants were 3.2 and 1.4 times higher in plants of the wild population than in the cultivated and feral populations, respectively (Fig. 1). Furthermore, concentrations of all individual compounds were significantly differ- ent among the three populations (statistics not shown, but all significance levels were lower than 0.05).

Differences between the cultivated and feral populations on the one side, and the wild population on the other side, became even more pronounced after the plants were induced by larval P. xylostella feeding (Fig. 1). In the cultivated and feral plants, total levels of GS remained at similar levels before and after induction by $P$. xylostella feeding (cultivar: $t_{50}=0.82, P=0.42$; feral population: $t_{50}=$ $0.39, P=0.70$ ), whereas in the wild population, concentrations were $1.5-2$ times higher after herbivore feeding $\left(t_{50}=3.11, P<0.001\right)$. Levels of individual GS changed differentially in response to herbivore feeding. The indole GS, glucobrassicin, was induced by $P$. xylostella feeding in all the plant populations $\left(t_{50}=6.90, P<0.001\right)$. Moreover, glucobrassicin accounted for almost $70 \%$ of the GS composition in the wild population after induction, and for only $53 \%$ and $35 \%$ in the cultivated and feral population, respectively. In contrast, the relative amount of glucobrassicin in undamaged plants was only $21 \%, 5 \%$, and $25 \%$ in the cultivated, feral, and wild populations, respectively. A second indole GS, neoglucobrassicin, was also induced in response to herbivory in the feral $\left(t_{50}=2.55\right.$, $P=0.01)$ and the wild population $\left(t_{50}=4.76, P<0.001\right)$, but not in the cultivated population $\left(t_{50}=0.37, P=0.71\right)$ in which levels of this compound were very low.

Not all GS concentrations increased after herbivory. Sinigrin was reduced after $P$. xylostella larval feeding in the cultivated $\left(t_{50}=2.4, P=0.02\right)$ and the wild population $\left(t_{50}=\right.$ 3.67, $P<0.001)$, but not in the feral population $\left(t_{50}=0.07\right.$, $P=0.95)$. Similarly, levels of glucoiberin decreased in response to $P$. xylostella feeding in the cultivar $\left(t_{50}=2.79\right.$, $P=0.007)$ and the wild population $\left(t_{50}=4.22, P<0.001\right)$, but not in the feral population $\left(t_{50}=0.02, P=0.99\right)$. In the feral population, both sinigrin and glucoiberin were present in much lower concentrations than in the other two populations (Fig. 1). In plants damaged by parasitized and unparasitized larvae of $P$. xylostella, concentrations of individual GS were not significantly different (statistics not shown, but all significance levels were lower than $0.05)$.

Insect Performance: Herbivores In P. xylostella, plant population and sex had an effect on egg-to-adult development time (plant population: $F_{2,131}=5.95, P=0.003$; sex: $F_{1,131}=5.52, P=0.02$; Fig. 2a). Female $P$. xylostella developed faster than males; the fastest development time was observed for females reared on the cultivated and the feral population. For adult biomass, the interaction between plant population and sex was significant $\left(F_{2,132}=11.1, P<\right.$ 0.001). Plant population had a strong effect on female but not on male biomass (Fig. 2b). The heaviest females were 
Undamaged $(n=6)$

․ P. xylostella $(\mathrm{n}=5)$

口 Parasitized P. xylostella $(\mathrm{n}=9)$

\section{a}
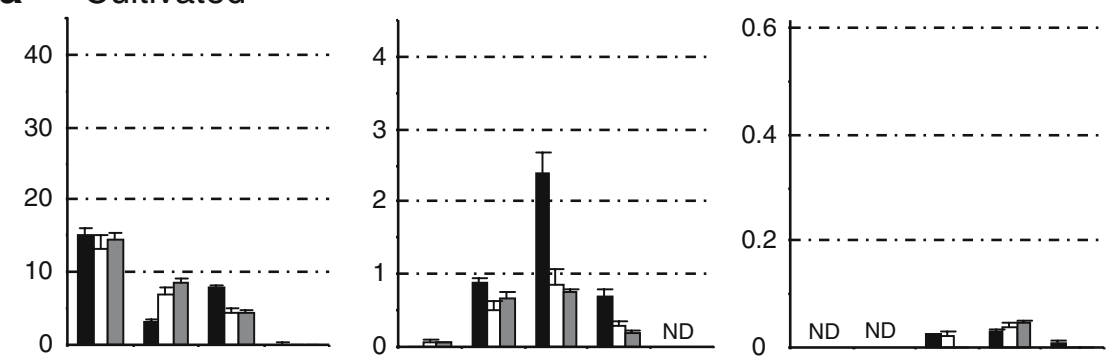

Feral
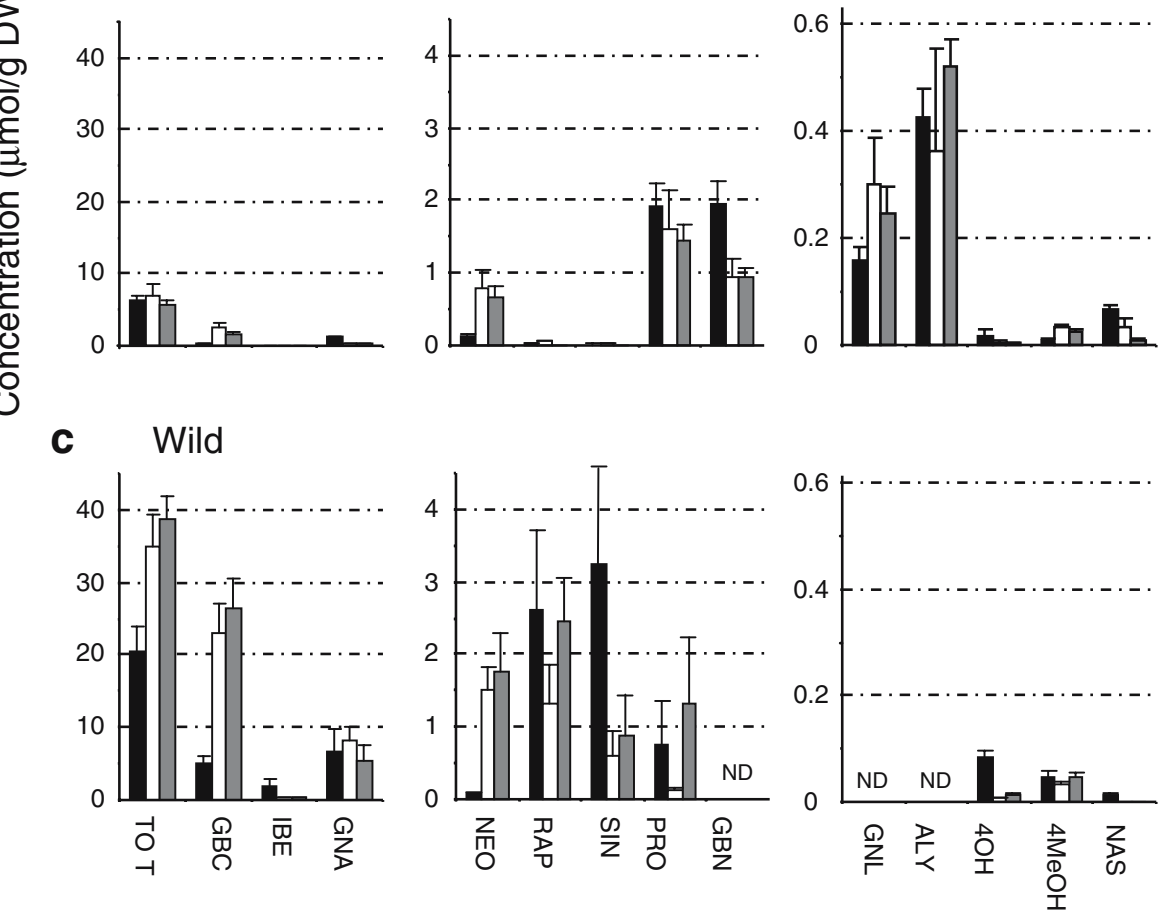

\section{Glucosinolates}

Fig. 1 Glucosinolate (GS) concentrations (mean \pm SE) in leaf tissues of a cultivated (a), feral (b), and wild (c) Brassica population. Concentrations were measured in leaf tissue from plants that were undamaged (black bars), damaged by unparasitized P. xylostella larvae (white bars) and damaged by parasitized (D. semiclausum) larvae (gray bars). GS abbreviations and scientific names: TOT total GS concentration, $G B C$ glucobrassicin (= indol-3-ylmethyl GS), IBE glucoiberin (= 3-methylsulfinyl propyl GS), GNA gluconapin (=3butenyl GS), NEO neoglucobrassicin (= 1-methoxyindol-3-ylmethyl

recovered from the cultivar, and the lightest from the wild population. In contrast, males were significantly lighter than females $\left(F_{1,132}=317, P<0.001\right)$ and obtained similar biomasses on all three plant populations (Fig. 2b). For $P$. xylostella, plant population did not affect larval survival to the adult stage $\left(\chi^{2}=0.96, d f=2, P=0.62\right.$, Fig. 3$)$.

Development time also varied with the population on which the $P$. rapae larvae had been reared $\left(F_{2,105}=7.8, P<\right.$ 0.001 , Fig. 4a). Egg-to-adult development time of males
GS), $R A P$ glucoraphanin (= 4-methylsulfinyl butyl GS), SIN sinigrin (= 2-propenyl GS), $P R O$ progoitrin (= 2(R)-2-hydroxy-3-butenyl GS), $G B N$ glucobrassicanapin (= 4-pentenyl GS), GNL gluconapoleiferin (= 2-hydroxy-4-pentenyl GS), $A L Y$ glucoallyssin (= 5-methylsulfinyl pentyl GS), 4OH 4-hydroxyglucobrassicin (= 4-hydoxyindol-3ylmethyl GS), 4MeOH, 4-methoxyglucobrassicin (= 4-methoxyindol3-ylmethyl GS), and $N A S$ gluconasturcin (=2-phenylethyl GS). ND not detectable

was shortest on the cultivar, longer on the feral, and longest on the wild population (Fig. 4a). Males took longer to complete their development than females $\left(F_{1,105}=7.5, P=\right.$ 0.007). Plant population also had a significant effect on adult biomass $\left(F_{2,101}=17.5, P<0.001\right.$, Fig. $\left.4 b\right)$. Whereas adult biomass in $P$. rapae did not differ between the cultivated and the feral line, biomass of butterflies reared on the wild population was lower (Fig. 4b). On average, females were marginally heavier than males $\left(F_{1,101}=3.2\right.$, $P=0.08$ ). Irrespective of plant population, more than $92 \%$ 


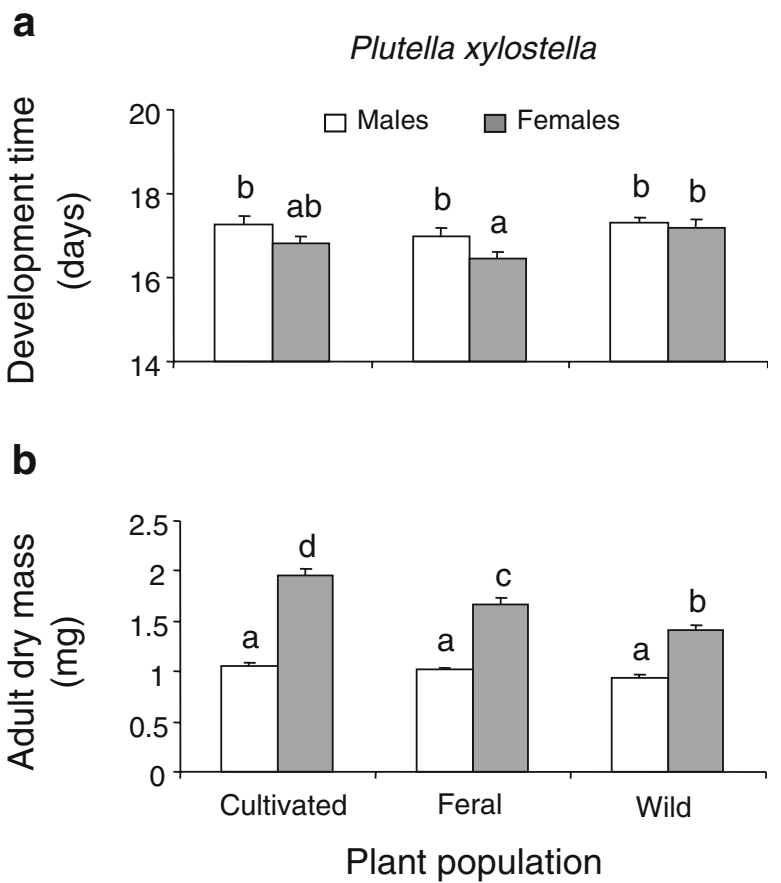

Fig. 2 Egg-to-adult development time (a) and adult dry mass (b) of $P$. xylostella males (white bars) and females (gray bars) reared on either a cultivated, a feral, or wild Brassica population. Bars (mean $\pm \mathrm{SE}$ ) with different letters are significantly different from each other (Tukey multiple comparisons, $\alpha=0.05)$. Numbers of individuals $(N)$ were on the cultivar, escape, and wild population, respectively: males, 21, 22, and 31 ; females $23,22,18$

of all $P$. rapae larvae successfully developed into adults, and survival rates were not significantly different $\left(\chi^{2}=0.22\right.$, $d f=2, P=0.90$, Fig. 3).

In the case of the generalist herbivore, $M$. brassicae, the effect of host-plant population on adult biomass was more pronounced compared to the two specialists. It is difficult to determine the sex of adult moths, therefore, the data were pooled. Adult mass on the cultivated line was twice as high,

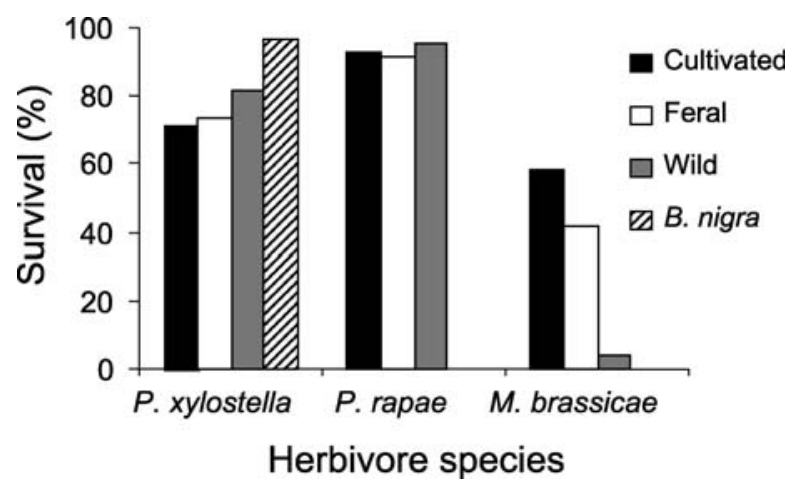

Fig. 3 Larval to adult survival of two specialist herbivores, $P$. xylostella and P. rapae, and one generalist, Mamestra brassica, when reared on either a cultivated, feral or wild Brassica population. P. xylostella was also reared on a wild population of $B$. nigra

\section{a}

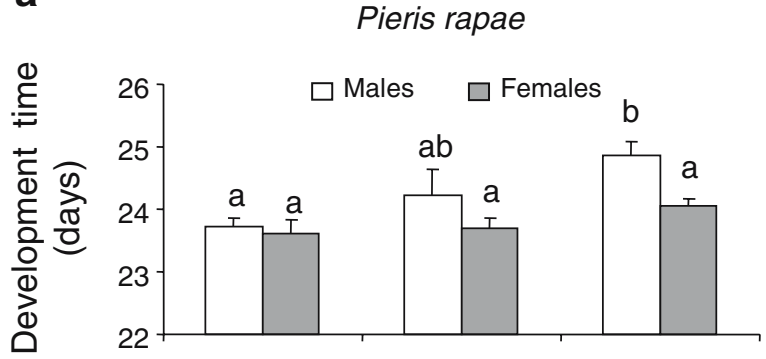

b

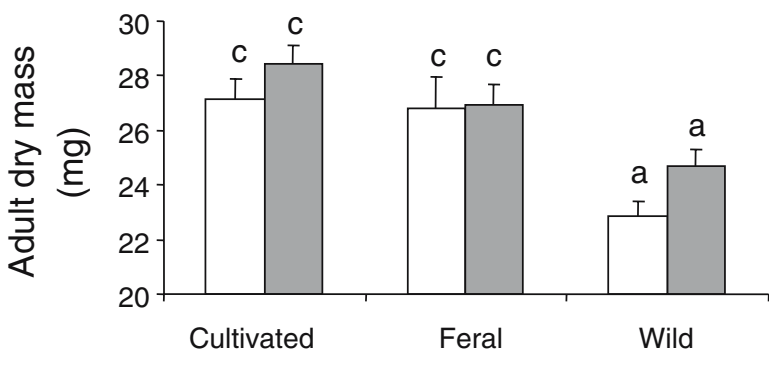

Plant population

Fig. 4 Egg-to-adult development time (a) and adult dry mass (b) of $P$. rapae males (white bars) and females (gray bars) reared on either a cultivated, feral, or wild Brassica population. Bars (mean $\pm \mathrm{SE}$ ) with different letters are significantly different from each other (Tukey multiple comparisons, $\alpha=0.05)$. Numbers of individuals $(N)$ were on the cultivated, feral, and wild population, respectively: males, 22, 10, and 19 ; females $16,20,20$

compared to the wild population, and was also significantly higher on the feral population $\left(F_{2,}{ }_{49}=8.28, P<0.001\right.$, Fig. 5b). Plant population did not affect development time $\left(F_{2,49}=0.33, P=0.72\right.$, Fig. 5a). Unlike the two specialists, survival of $M$. brassicae was affected by plant population $\left(\chi^{2}=20.4, d f=2, P<0.001\right.$, Fig. 3$)$. The percentage of $M$. brassicae larvae that developed successfully into adults was highest on the cultivated population (58\%), slightly lower on the feral population $(42 \%)$, and the smallest $(4 \%)$ on the wild population.

Insect Performance: Parasitoids In the specialist parasitoid, D. semiclausum, plant population had an effect on eggto-adult development time $\left(F_{2}, 275=6.49, P=0.002\right.$, Fig. 6a). The parasitoid developed fastest on the feral population and developed more slowly on the cultivated and wild populations of B. oleracea (Fig. 6a). Egg-to-adult development time was longer in females than in males $\left(F_{1,275}=13.0, P<0.001\right)$. Furthermore, plant population had an effect on adult biomass in D. semiclausum, $\left(F_{2,277}=\right.$ 11.3, $P<0.001$, Fig. 6b). The heaviest $D$. semiclausum wasps emerged from hosts that were reared on the cultivated population, whereas the lightest emerged from host reared on the wild and feral populations. D. semiclausum females were heavier than males $\left(F_{1,277}=57.4\right.$, 


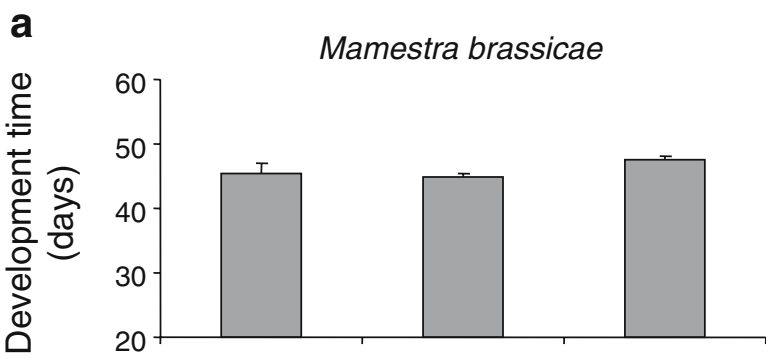

b

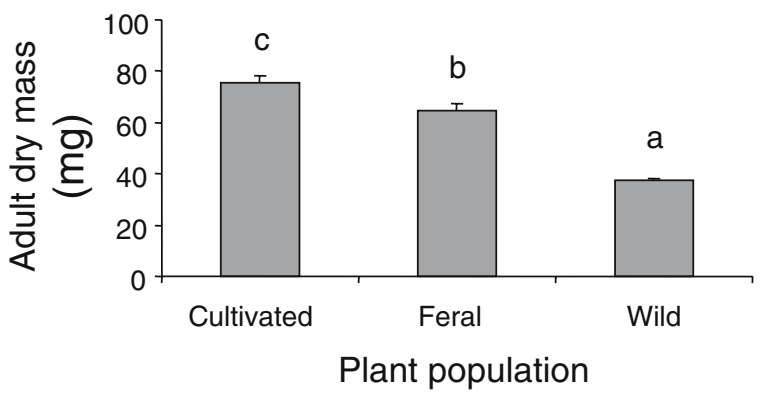

Fig. 5 Egg-to-adult development time (a) and adult dry mass (b) of M. brassicae reared on either a cultivated, feral, or wild Brassica population. Bars (mean $\pm \mathrm{SE}$ ) with different letters are significantly different from each other (Tukey multiple comparisons, $\alpha=0.05$ ). Numbers of individuals $(N)$ were on the cultivated, feral, and wild population, respectively: 21,29 , and 2

$P<0.001)$. Between 67 and $80 \%$ D. semiclausum successfully completed development to eclosion on the three Brassica populations (Fig. 7). Survival rates were not significantly different on the three plant populations $\left(\chi^{2}=\right.$ $3.77, d f=2, P=0.15)$.

As with $D$. semiclausum, egg-to-adult development time in $D$. fenestrale varied with plant population $\left(F_{2,69}=5.27\right.$, $P=0.007$, Fig. 8a). However, dry mass in male $D$. fenestrale wasps did not vary significantly with the population on which the hosts had been reared $\left(F_{2,}{ }_{69}=0.25, P=0.78\right.$, Fig. $8 \mathrm{~b}$ ). As only thirteen $D$. fenestrale females in total successfully developed, data on females were excluded from the analysis and are not presented in the figures. The most dramatic effect of plant population was on the survival of $D$. fenestrale (Fig. 7), which was significantly different for the three plant populations $\left(\chi^{2}=12.2, d f=2, P=0.002\right)$. Only $9 \%$ of the parasitized hosts reared on the wild population successfully produced $D$. fenestrale wasps. By contrast, $33 \%$ survived on the cultivar and $16 \%$ on the feral population. Moreover, the lowest number of surviving $D$. fenestrale parasitoids, eight out of 172 (or 4.6\%), was obtained on B. nigra. Male wasps $(N=5)$ developing in hosts reared on $B$. nigra plants were lighter $(0.432 \pm$ $0.033 \mathrm{mg}$, mean $\pm \mathrm{SE})$ and developed slower $(17.8 \pm 0.37$ d) than males reared from hosts on B. oleracea (see Fig. 6). a
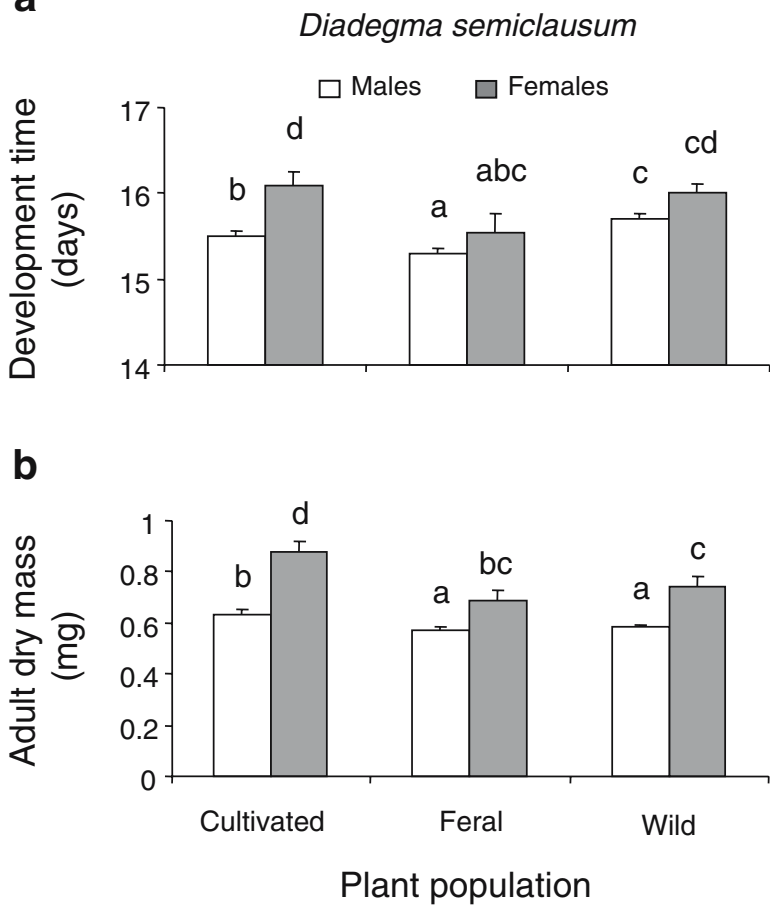

Fig. 6 Egg-to-adult development time (a) and adult dry mass (b) of D. semiclausum males (white bars) and females (gray bars) reared on P. xylostella feeding on either a cultivated, feral, or wild Brassica population. Bars (mean $\pm \mathrm{SE}$ ) with different letters are significantly different from each other (Tukey multiple comparisons, $\alpha=0.05$ ). Numbers of individuals $(N)$ were on the cultivated, feral, and wild population, respectively: 87,69 , and 81 for males and $11,12,10$ for females

In contrast, healthy $P$. xylostella moths performed better on $B$. nigra than on B. oleracea, in terms of survival (97\%, Fig. 3) and adult mass, $1.985 \pm 0.068 \mathrm{mg}(N=16)$ and $1.104 \pm$ $0.068 \mathrm{mg}(N=16)$, for females and males, respectively (see also Fig. 2b). However, development time, $17.8 \pm 0.26 \mathrm{~d}$ for both female and male moths, was slightly longer (see also Fig. 2a).

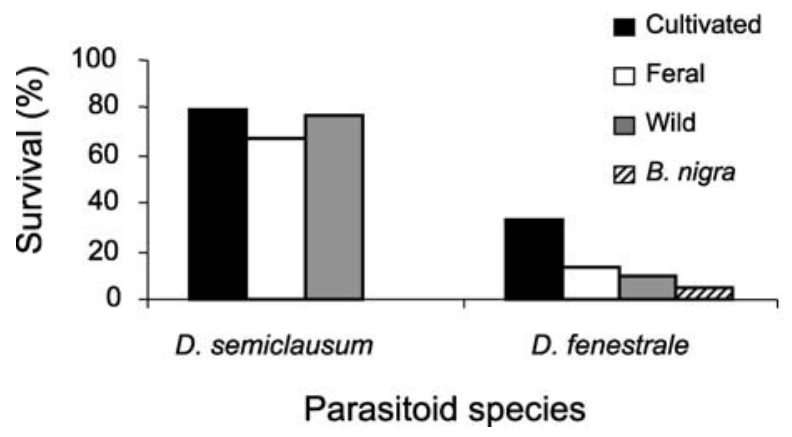

Fig. 7 Egg-to-adult survival of a specialist parasitoid, D. semiclausum, and a generalist parasitoid, D. fenestrale, when reared from the host, P. xylostella, on either a cultivated, feral, or wild Brassica population. $D$. fenestrale was also reared from $P$. xylostella on a wild population of $B$. nigra 


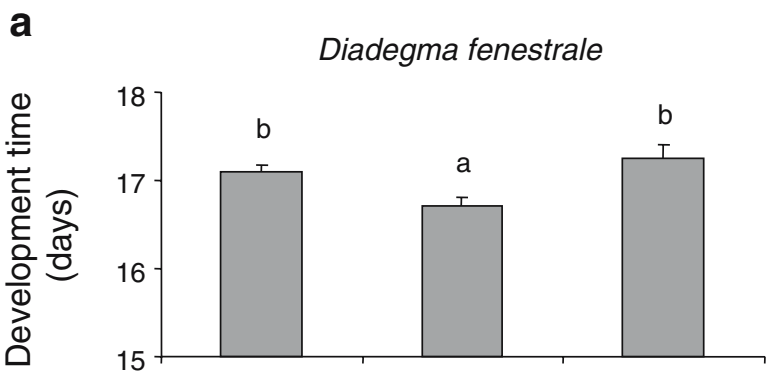

b

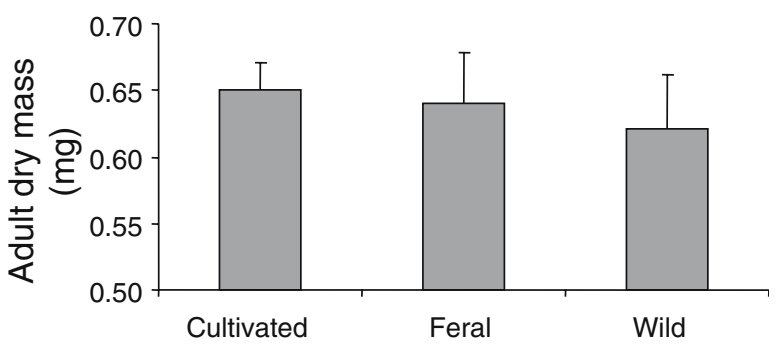

Plant population

Fig. 8 Egg-to-adult development time (a) and adult dry mass (b) of $D$. fenestrale males reared on $P$. xylostella feeding on either a cultivated, feral, or wild Brassica population. Bars (mean $\pm \mathrm{SE}$ ) with different letters are significantly different from each other (Tukey multiple comparisons, $\alpha=0.05)$. Numbers of individuals $(N)$ were on the cultivar, escape, and wild population, respectively: 44,18 , and 14

\section{Discussion}

Through artificial selection via domestication, levels of primary and secondary compounds in domesticated plants are often altered compared with their progenitors. The results of this study revealed that GS concentrations in leaf tissue varied significantly among the three different plant populations. Much higher concentrations of GS were recorded in wild B. oleracea than in cultivated and feral population. GS levels in the wild population studied in this paper were similar to concentrations reported earlier in other wild populations of $B$. oleracea (Mithen et al. 1995; Moyes et al. 2000). The most striking differences in GS concentrations were observed after induction by herbivore feeding, especially in the wild population. In wild plants, total GS concentrations were 1.7 times higher in induced plants than in uninduced conspecific plants, and were 2.7 and 4.9 times higher after herbivory than in induced plants of the cultivated and feral population, respectively. By contrast, the total GS concentrations in induced plants remained at the same level as in undamaged plants in the cultivated and feral populations, although differences were found for levels of individual compounds.

The feral population differed from the other two populations with respect to pentyl-derived GS, which were absent in the cultivated and wild population. These C5 GS usually are not found in B. oleracea crops (Rosa 1999), indicating that this population may have crossed with a closely related species such as B. napus or B. rapa, both of which contain pentyl GS (Giamoustaris and Mithen 1995). Moreover, both B. napus and B. rapa are cultivated and grow naturally in the Netherlands. In all plant populations, concentrations of the indole GS, glucobrassicin, increased the most after herbivore feeding, but this compound was dominant only in the wild population, accounting for $70 \%$ of the GS content. Several studies have reported on herbivoreinduced changes in GS concentrations in both cultivated and wild brassicaceous species. In line with our results, previous studies have shown that levels of indole GS increase in response to insect wounding (Bodnaryk 1992; Agrawal et al. 1999; Bartlet et al. 1999; Gols et al. 2008). We found that concentrations of some of the aliphatic GS were lower in plants that had been damaged by $P$. xylostella than in undamaged plants. Previous studies that used different herbivores reported that levels of aliphatic GS were either unaffected (Bodnaryk 1992; Bartlet et al. 1999; Traw and Dawson 2002; Gols et al. 2008) or even increased (Traw and Dawson 2002) in response to insect wounding. These results suggest differential induction of aliphatic GS by different herbivores (see also Traw and Dawson 2002).

Glucosinolates also play a major role in determining a plant's nutritional quality, not only for humans and livestock but also for pathogens and insect herbivores (Chew 1988; Mithen 1992). This study shows that plants from a wild population of $B$. oleracea are less suitable for the development of several herbivores than plants from a cultivated and a feral population. However, the severity of these effects differed between the specialists $P$. rapae and $P$. xylostella on one hand, and the generalist $M$. brassicae on the other. In P. rapae, emerging adult butterflies were smaller and took longer to complete development when reared on wild plants than on the other two populations. These effects were less pronounced in P. xylostella; however, where adult body mass was more negatively affected than development time. Importantly, in both of the specialist herbivores, survival was high, irrespective of the plant population on which the larvae had been reared. By contrast, adult body mass and survival in the generalist herbivore, M. brassicae, were significantly lower when reared on the wild $B$. oleracea strain. This reveals that costs in terms of reduced fitness are higher for generalist herbivores than for specialists when they feed on the more toxic wild plants. Similarly, Giamoustaris and Mithen (1995) found a negative relationship between GS content in oilseed rape (B. napus) and the amount of leaf damage by generalist herbivores, but a positive relationship for specialists. Levels of GS, especially indole GS, were higher in the wild population of $B$. oleracea than levels of GS found in B. napus by Giamoustaris and Mithen (1995). These results suggest that indole GS, 
especially neoglucobrassicin, which is present in very low concentrations in the cultivar, may play a role in reducing the performance of insect herbivores.

Specialist insect herbivores, in contrast with generalists, may use GS as indicators of host plant suitability. For example, GS serve as feeding stimulants for insect herbivores specialized on plants belonging to the Brassicaceae (Nayar and Thorsteinson 1963; David and Gardiner 1966; Renwick and Lopez 1999). However, not all GS are equally active as feeding stimulants (e.g., Nayar and Thorsteinson 1963), and high levels of GS can even be toxic for specialists (Agrawal and Kurashige 2003). As such, high levels of specific GS may be responsible for the reduced performance of the specialists $P$. xylostella and $P$. rapae when reared on the wild population. Furthermore, levels of the enzyme myrosinase, which catalyzes hydrolysis of GS into the more toxic (iso)thiocyanates and nitriles (Rask et al. 2000; Mithen 2001), may also have differed among the populations. In addition, host plant quality is not determined only by the presence of allelochemicals. Nutrients, such as proteins and carbohydrates, as well as digestibility reducers, also play a role (Slansky 1993). It is possible that levels of limiting nutrients such as nitrogen and other defense-related compounds also vary across the three populations and thus amplify differences in performance caused by GS (Slansky and Feeny 1977).

The performance of the two parasitoid species reared on $P$. xylostella also varied with the plant population on which the host had been reared. However, there were also significant differences in performance between the specialist parasitoid, D. semiclausum, and the congeneric generalist parasitoid, $D$. fenestrale. The development of $D$. semiclausum was directly affected by the development of the host. Adult body mass was reduced when developing on wild $B$. oleracea plants, whereas development time and survival were unaffected, revealing that $D$. semiclausum ontogeny is affected by quantitative changes in host quality as mediated through the diet of their host. Alternatively, the development of $D$. fenestrale was characterized less by direct differences in host quality than by indirect population-related variations in plant quality. Although $P$. xylostella survival was high $(>80 \%)$ on all B. oleracea populations, as well as on $B$. nigra plants, mortality in $D$. fenestrale was much higher on the wild Brassica populations.

As in most endoparasitoids, larvae of $D$. fenestrale primarily consume host hemolymph and fat body during early development. They only begin to indiscriminately attack other tissues later during development (the so-called "destructive feeding phase"). In this way, they do not kill the host until the last possible moment. Larvae of $P$. xylostella are known to utilize enzymes that convert GS into desulfo-GS in their gut, which are then excreted with their feces (Ratzka et al. 2002). Because of their polarity,
GS presumably do not permeate the host-gut membrane but effectively remain in the gut before they are excreted. Consequently, the larvae of $D$. fenestrale probably ingest little, if any, GS when feeding on hemolymph. However, during the destructive feeding phase, the parasitoid larvae undoubtedly consume the host gut and its contents, and this is when the toxic effects of plant allelochemicals on non-adapted parasitoids may be realized. In hosts parasitized by $D$. fenestrale, mortality mainly occurred just before the parasitoids would have been expected to pupate (personal observation) supporting this argument. Furthermore, the gut of endoparasitoid larvae is not externally connected until after emergence from the host. The excretion of wastes into internal host tissues would facilitate bacterial infection and precocious death of both the host and the developing parasitoid (Harvey et al. 2003). Thus, low concentrations of allelochemicals that are ingested by parasitoid larvae are stored and presumably accumulate in their tissues. This may account for the high mortality recorded here with $D$. fenestrale that developed in $P$. xylostella caterpillars reared on mustard and wild cabbage plants, which contain high levels of GS.

All insects used in this study have been reared on the Cyrus cultivar for many generations and may have adapted to this plant population. However, P. xylostella developed more successfully on B. nigra plants than on the cultivar, with moths enjoying higher survival and larger body mass. Furthermore, the performance of Mamestra brassicae and Pieris rapae was almost similar on the feral and the cultivated population. We cannot exclude that the observed differences are the result of rearing history rather than true plant effects, but the fact that the insects have no history with the recently cultivated feral population of $B$. oleracea and developed with equal success as on the cultivar suggests that plant quality is affected by domestication. Moreover, the development of the insects was more strongly negatively affected on the wild "Old Harry" population than on the feral population.

In summary, this study has shown that plant quality in terms of development of herbivores and their natural enemies differs significantly between wild and cultivated populations of B. oleracea. The identity of the food plant and the degree of specialization exhibited by the herbivores and their parasitoids influenced the degree to which plant population affected performance. Most importantly, these results demonstrate that artificial selection in which certain plant traits are accentuated at the expense of others can alter a significant part of a plant's evolved physiology. This may in turn have large impacts on insect communities that are associated with these plants. In wild plants, defense mechanisms have evolved under natural selection pressures from herbivores and pathogens and by the effects of natural enemies on herbivore populations. The reduction of the levels of direct defenses in cultivated plants could partly 
explain why these plants have often become more susceptible to attack from a wide range of herbivores and pathogens. To better understand the relative contribution of insect herbivory as a selective agent on the evolution of plant defenses, these traits should be studied in wild populations in which defense mechanisms have not been constrained by the "directional selection" that characterizes many species of crop plants. Future studies should examine insect communities associated with plant populations, including cultivars that differ in resistance against insect herbivores in plots in which the structural heterogeneity is also manipulated. This will facilitate a better understanding of the role that artificial selection has played in shaping the structure of communities associated with cropping systems.

Acknowledgments The authors thank André Gidding and Leo Koopman for rearing the insects and Unifarm for rearing the plants. Ciska Raaijmakers from the Netherlands Institute of Ecology is acknowledged for her assistance in the GS analyses.

Open Access This article is distributed under the terms of the Creative Commons Attribution Noncommercial License which permits any noncommercial use, distribution, and reproduction in any medium, provided the original author(s) and source are credited.

\section{References}

Agrawal, A. A. 1999a. Induced plant defense: Evolution of induction and adaptive phenotypic plasticity, pp. 251-268, in A. A. Agrawal, S. Tuzun, and E. Bent (eds.). Induced Plant Defenses Against Pathogens and Herbivores. Biochemistry, Ecology and AgricultureAPS Press, St. Paul, Minnesota.

AgraWAL, A. A. 1999b. Induced responses to herbivory in wild radish: Effects on several herbivores and plant fitness. Ecology 80:1713-1723

Agrawal, A. A., and Kurashige, N. S. 2003. A role for isothiocyanates in plant resistance against the specialist herbivore Pieris rapae. J. Chem. Ecol. 29:1403-1415.

Agrawal, A. A., Strauss, S. Y., and Stout, M. J. 1999. Costs of induced responses and tolerance to herbivory in male and female fitness components of wild radish. Evolution 53:1093-1104.

AzIDAh, A. A., Fitton, M. G., and Quicke, D. L. J. 2000. Identification of the Diadegma species (Hymenoptera: Ichneumonidae, Campopleginae) attacking the diamondback moth, Plutella xylostella (Lepidoptera: Plutellidae) . Bull. Entomol. Res. 90:375-389.

Barbosa, P., Saunders, J. A., Kemper, J., Trumbule, R., OlechNO, J., and MARTINAT, P. 1986. Plant allelochemicals and insect parasitoids: Effects of nicotine on Cotesia congregata (Say) (Hymenoptera, Braconidae) and Hyposoter annulipes (Cresson) (Hymenoptera, Ichneumonidae). J. Chem. Ecol. 12:1319-1328.

BArbosA, P., Gross, P., and KeMPer, J. 1991. Influence of plant allelochemicals on the tobacco hornworm and its parasitoid, Cotesia congregate. Ecology 72:1567-1575.

Bartlet, E., Kiddle, G., Williams, I., and Wallsgrove, R. 1999. Wound-induced increases in the glucosinolate content of oilseed rape and their effect on subsequent herbivory by a crucifer specialist. Entomol. Exp. Appl. 91:163-167.
Benrey, B., Callejas, A., Rios, L., Oyama, K., and Denno, R. F. 1998. The effects of domestication of Brassica and Phaseolus on the interaction between phytophagous insects and parasitoids. Biol. Control 11:130-140.

Blau, P. A., Feeny, P., Contardo, L., and Robson, D. S. 1978. Allylglucosinolate and herbivorous caterpillars: A contrast in toxicity and tolerance. Science 200:1296-1298.

BODNARYK, R. P. 1992. Effects of wounding on glucosinolates in the cotyledons of oilseed rape and mustard. Phytochemistry 31:2671-2677.

CHEW, F. S. 1988. Biological effects of glucosinolates, pp. 155-181, in H. G. Cutler (ed.). Biologically Active Natural Products for Potential Use in AgricultureAmerican Chemical Society, Washington.

DAVID, W. A. L., and GARDINER, B. O. 1966. Mustard oil glucosides as feeding stimulants for Pieris brassicae larvae in a semisynthetic diet. Entomol. Exp. Appl. 9:247-255.

De Moraes, C. M., Lewis, W. J., Pare, P. W., Alborn, H. T., and TumLInson, J. H. 1998. Herbivore-infested plants selectively attract parasitoids. Nature 393:570-573.

EC. 1990. Oil seeds — determination of glucosinolates High Performance Liquid Chromatography. Official Journal of the European Communities L 170/28. Annex VIII:03.07.27-34.

Evans, L. T. 1993. Crop Evolution, Adaptation and Yield. Cambridge University Press.

FAHEY, J. W., ZalcmanN, A. T., and Talalay, P. 2002. The chemical diversity and distribution of glucosinolates and isothiocyanates among plants. Phytochemistry 59:237-237.

Francis, F., Lognay, G., Wathelet, J. P., and Haubruge, E. 2001. Effects of allelochemicals from first (Brassicaceae) and second (Myzus persicae and Brevicoryne brassicae) trophic levels on Adalia bipunctata. J. Chem. Ecol. 27:243-256.

Geervliet, J. B. F., Verdel, M. S. W., Snellen, H., Schaub, J., Dicke, M., and VeT, L. E. M. 2000. Coexistence and niche segregation by field populations of the parasitoids Cotesia glomerata and C. rubecula in the Netherlands: Predicting field performance from laboratory data. Oecologia 124:55-63.

GIAMOUSTARIS, A., and Mithen, R. 1995. The effect of modifying the glucosinolate content of leaves of oilseed rape (Brassica napus ssp oleifera) on its interaction with specialist and generalist pests. Ann. Appl. Biol. 126:347-363.

Gols, R., Bukovinszky, T., Hemerik, L., Harvey, J. A., VAN LENTEREN, J. C., and VET, L. E. M. 2005. Reduced foraging efficiency of a parasitoid under habitat complexity: Implications for population stability and species coexistence. J. Anim. Ecol. 74:1059-1068.

Gols, R., WagenaAR, R., Bukovinszky, T., VAn Dam, N. M., Dicke, M., Bullock, J. M., and HarveY, J. A. 2008. Genetic variation in the defense chemistry of wild cabbage populations and its effects on native herbivores and their endoparasitoids. Ecology, in press.

GÓMEZ-CAMPO, C., and PRAKASH, S. 1999. Origin and domestication, pp. 33-58, in C. Gomez-Campo (ed.). Developments in Plant Genetics and Breeding, 4. Biology of Brassica Coenospecies. Elsevier, Amsterdam.

HARVEY, J. A., VAN DAM, N. M., and GOLS, R. 2003. Interactions over four trophic levels: Foodplant quality affects development of a hyperparasitoid as mediated through a herbivore and its primary parasitoid. J. Anim. Ecol. 72:520-531.

Harvey, J. A., Van Nouhuys, S., and Biere, A. 2005. Effects of quantitative variation in allelochemicals in Plantago lanceolata on development of a generalist and a specialist herbivore and their endoparasitoids. J. Chem. Ecol. 31:287-302.

Harvey, J., Gols, R., WagenaAr, R., and Bezemer, T. 2007. Development of an insect herbivore and its pupal parasitoid reflect differences in direct plant defense. J. Chem. Ecol. $33: 1556-1569$. 
JoHnSON, K. S. 1999. Comparative detoxification of plant (Magnolia virginiana) allelochemicals by generalist and specialist Saturniid silkmoths. J. Chem. Ecol. 25:253-269.

KARBAN, R., and BALDWIN, I. T. 1997. Induced Responses to Herbivory. University of Chicago Press, Chicago.

Khan, Z. R., Ampongnyarko, K., Chiliswa, P., Hassanali, A., Kimani, S., Lwande, W., Overholt, W. A., Pickett, J. A., SMART, L. E., WAdHAMS, L. J., and WoOdCOCK, C. M. 1997. Intercropping increases parasitism of pests. Nature 388:631-632.

Krieger, R. I., Feeny, P. P., and Wilkinson, C. F. 1971. Detoxication enzymes in guts of caterpillars: An evolutionary answer to plant defenses. Science 172:579-581.

Kushad, M. M., Brown, A. F., Kurilich, A. C., JuviK, J. A., Klein, B. P., Wallig, M. A., and JefFery, E. H. 1999. Variation of glucosinolates in vegetable crops of Brassica oleracea. J. Agric. Food Chem. 47:1541-1548.

LEGASPI, B. A. C. 1986. Host discrimination in two species of ichneumonid wasps, Diadegma spp., attacking larvae of Plutella xylostella. Entomol. Exp. Appl. 41:79-82.

Li, Q., Eigenbrode, S. D., Stringham, G. R., and Thiagarajah, M. R. 2000. Feeding and growth of Plutella xylostella and Spodoptera eridania on Brassica juncea with varying glucosinolate concentrations and myrosinase activities. J. Chem. Ecol. 26:2401-2419.

Mitchell, N. D. 1976. The status of Brassica oleracea subsp. oleracea (wild cabbage) in the British Isles. Watsonia 11:97-103.

Mitchell, N. D., and RichardS, A. J. 1979. Biological flora of the British isles-Brassica oleracea L. ssp. oleracea (B. sylvestris (L.) Miller). J. Ecol. 67:1087-1096.

MitHEN, R. 1992. Leaf glucosinolate profiles and their relationship to pest and disease resistance in oilseed rape. Euphytica 63:71-83.

MithEN, R. F. 2001. Glucosinolates and their degradation products. Adv. Bot. Res. 35:213-262.

Mithen, R., Raybould, A. F., and Giamoustaris, A. 1995. Divergent selection for secondary metabolites between wild populations of Brassica oleracea and its implications for plantherbivore interactions. Heredity 75:472-484.

Moyes, C. L., Collin, H. A., Britton, G., and Raybould, A. E. 2000. Glucosinolates and differential herbivory in wild populations of Brassica oleracea. J. Chem. Ecol. 26:2625-2641.

Müller, C., Agerbirk, N., Olsen, C. E., Boevé, J. L., Schaffner, U., and BRAKEFIELD, P. M. 2001. Sequestration of host plant glucosinolates in the defensive hemolymph of the sawfly Athalia rosae. J. Chem. Ecol. 27:2505-2516.

NAYAR, J. K., and THORSTEINSON, A. J. 1963. Further investigations into the chemical basis of insect-host plant relationships in an oligophagous insect, Plutella maculipennis (Curtis) (LepidopteraPlutellidae). Can. J. Zool. 41:923-929.

ODE, P. J. 2006. Plant chemistry and natural enemy fitness: Effects on herbivore and natural enemy interactions. Annu. Rev. Entomol. $51: 163-185$.

Ode, P. J., Berenbaum, M. R., Zangerl, A. R., and Hardy, C. W. 2004. Host plant, host plant chemistry and the polyembryonic parasitoid Copidosoma sosares: Indirect effects in a tritrophic interaction. Oikos 104:388-400.

RASK, L., ANDREASSON, E., EKBOM, B., ERIKSSON, S., PONTOPPIDAN, B., and MeIJER, J. 2000. Myrosinase: Gene family evolution and herbivore defense in Brassicaceae. Plant Mol. Biol. 42:93-113.
RatzKa, A., Vogel, H., Kliebenstein, D. J., Mitchell-Olds, T., and KroymanN, J. 2002. Disarming the mustard oil bomb. Proc. Natl. Acad. Sci. U. S. A. 99:11223-11228.

ReNwick, J. A. A., and LopeZ, K. 1999. Experience-based food consumption by larvae of Pieris rapae: Addiction to glucosinolates? Entomol. Exp. Appl. 91:51-58.

RooT, R. B. 1973. Organization of a plant-arthropod association in simple and diverse habitats: The fauna of collards (Brassica oleracea). Ecol. Monogr. 43:95-120.

RosA, E. A. S. 1999. Chemical composition, pp. 315-357, in C. Gomez-Campo (ed.). Developments in Plant Genetics and Breeding, 4. Biology of Brassica Coenospecies. Elsevier Science B.V., Amsterdam.

Schoonhoven, L. M., van Loon, J. J. A., and Dicke, M. 2005. Insect-Plant Biology (2nd ed.). Oxford University Press, USA.

SHEEHAN, W. 1986. Response by specialist and generalist natural enemies to agroecosystem diversification-a selective review. Environ. Entomol. 15:456-461.

SLANSKY, F. 1993. Nutritional ecology: The fundamental quest for nutrients, pp. 29-91, in N. E. Stamp, and T. M. Casey (eds.). Caterpillars: Ecological and Evolutionary Constraints on ForagingChapman and Hall, New York.

SLANSKY, F., and FEENY, P. 1977. Stabilization of the rate of nitrogen accumulation by larvae of the cabbage butterfly on wild and cultivated food plants. Ecol. Monogr. 47:209-228.

SONG, K., Osborn, T. C., and Williams, P. H. 1990. Brassica taxonomy based on nuclear restriction fragment length polymorphisms (Rflps). 3. Genome relationships in Brassica and related genera and the origin of Brassica oleracea and B. rapa (syn campestris). Theor. Appl. Genet. 79:497-506.

STOwE, K. A. 1998. Realized defense of artificially selected lines of Brassica rapa: Effects of quantitative genetic variation in foliar glucosinolate concentration. Environ. Entomol. 27:1166-1174.

Takabayashi, J., Dicke, M., and Posthumus, M. A. 1994. Volatile herbivore-induced terpenoids in plant mite interactions: Variation caused by biotic and abiotic factors. J. Chem. Ecol. 20:1329-1354.

Thaler, J. S., Stout, M. J., Karban, R., and Duffey, S. S. 2001. Jasmonate-mediated induced plant resistance affects a community of herbivores. Ecol. Entomol. 26:312-324.

TRAW, M. B., and DAWSON, T. E. 2002. Reduced performance of two specialist herbivores (Lepidoptera: Pieridae, Coleoptera: Chrysomelidae) on new leaves of damaged black mustard plants. Environ. Entomol. 31:714-722.

Turlings, T. C. J., Loughrin, J. H., McCall, P. J., Rose, U. S. R., LEWIS, W. J., and TumLinson, J. H. 1995. How caterpillardamaged plants protect themselves by attracting parasitic wasps. Proc. Natl. Acad. Sci. U. S. A. 92:4169-4174.

VAN DAM, N. M., WitJes, L., and Svatos, A. 2004. Interactions between aboveground and belowground induction of glucosinolates in two wild Brassica species. New Phytol. 161:801-810.

VAN Der MeIJden, E., and KlinkHamer, P. G. L. 2000. Conflicting interests of plants and the natural enemies of herbivores. Oikos 89:202-208.

Wittstock, U., Agerbirk, N., Stauber, E. J., Olsen, C. E., HiPPleR, M., MitCHELl-OldS, T., GERSHENSON, J., and Vogel, H. 2004. Successful herbivore attack due to metabolic diversion of a plant chemical defense. Proc. Natl. Acad. Sci. U. S. A. 101:4859-4864. 